\title{
Darwin's Explanation of Races by Means of Sexual Selection
}

Roberta L. Millstein

Department of Philosophy

One Shields Avenue

University of California, Davis

Davis, CA 95616 USA

RLMillstein@UCDavis.edu

http://www.RLM.net/

\section{Copyright by the author.}

Forthcoming in Studies in History and Philosophy of Biological and Biomedical Sciences

\author{
Abstract \\ In Darwin's Sacred Cause, Adrian Desmond and James Moore contend that "Darwin would put \\ his utmost into sexual selection because the subject intrigued him, no doubt, but also for a deeper \\ reason: the theory vindicated his lifelong commitment to human brotherhood" (2009: p. 360). \\ Without questioning Desmond and Moore's evidence, I will raise some puzzles for their view. I \\ will show that attention to the structure of Darwin's arguments in the Descent of Man shows that \\ they are far from straightforward. As Desmond and Moore note, Darwin seems to have intended \\ sexual selection in non-human animals to serve as evidence for sexual selection in humans. \\ However, Darwin's account of sexual selection in humans was different from the canonical cases \\ that Darwin described at great length. If explaining the origin of human races was the main \\ reason for introducing sexual selection, and if sexual selection was a key piece of Darwin's anti- \\ slavery arguments, then it is puzzling why Darwin would have spent so much time discussing \\ cases that did not really support his argument for the origin of human races, and it is also \\ puzzling that his argument for the origin of human races would be so (atypically) poor.
}




\section{Introduction}

Reading Adrian Desmond and James Moore's Darwin's Sacred Cause: How a Hatred of Slavery Shaped Darwin's Views on Human Evolution is like reading about someone vaguely familiar who existed in an alternate universe - a universe with humans at the center and pigeons, peacocks, and barnacles on the outskirts, instead of a universe with humans on the periphery. To make this case, Desmond and Moore seek to uncover the extent of Darwin's anti-slavery motivations - in their words, the "moral passion firing his evolutionary work."1 Indeed, Desmond and Moore's book amounts to no less than a call for a paradigm shift in the way we should think about Darwin - not as solely or even primarily motivated with explaining the facts of organisms in the natural world, but rather as being driven to provide the scientific underpinnings of the fight against slavery in the nineteenth century. ${ }^{2}$ It is a testament to Desmond and Moore's detailed examination of Darwin's drafts, notes, marginalia, letters, and published works, just how successful they are at effecting that paradigm shift - no small feat given people's entrenched views on Darwin. They exhaustively and convincingly show how, given Darwin's anti-slavery family and colleagues, together with heated debates over slavery occurring in England and the U.S., Darwin was clearly participating in a larger conversation that led him to try to explain the origin of human races. To cite just one of their examples, they ask us to rethink why Darwin began the Origin of Species with an extensive discussion of pigeons. The pigeon discussion is often interpreted as Darwin showing that a species can be quite variable (as required for natural selection) or laying the groundwork for an analogy between artificial

\footnotetext{
1 An anonymous referee suggests that Desmond and Moore do not make any claims about Darwin's motives, only claims about the "moral passion firing his evolutionary work," his "overwhelming impulse," and "the nucleus of his ${ }^{2}$ Or, as Radick (2009) describes Desmond and Moore's thesis, "slavery slips from the background to assume a leading role."
} 
selection and natural selection. But Desmond and Moore point out that pigeons had already been explicitly cited in discussions on human races, and that a reader at the time would have understood what Darwin was really talking about.

According to Desmond and Moore, Darwin sought to defend the anti-slavery position by arguing that humans were all the same species, sharing a common ancestry, contrary to the claims of some other scientists who held that the different races were actually different species, each specially created. This echoed the sentiment of the anti-slavery medallion created by Darwin's grandfather and displayed by Darwin's family and friends, which read, "Am I not a man and a brother?" Of course, Darwin didn't just argue that all humans had a common ancestor; he also argued that all organisms shared one (or at least a very few) common ancestors. Indeed, these two concerns often seemed to go together for Darwin, as reflected in his notebook B musings:

Animals whom we have made our slaves we do not like to consider our equals. - Do not slave holders wish to make the black man other kind? ...if we choose to let conjecture run wild then animals our fellow brethern in pain, disease, death \& suffering, \& famine, our slaves in the most laborious works, our companions in our amusements. they may partake from our origin in one common ancestor; we may be all netted together (231-2).

I am quite convinced by Desmond and Moore's suggestion that scholars have failed to appreciate the extent to which anti-slavery concerns motivated Darwin (which is not to say that I would go as far as Desmond and Moore, who imply that they were his primary motivations). I am also 
convinced that common descent played a key role in Darwin's anti-slavery arguments. ${ }^{3}$

However, I am less convinced by Desmond and Moore's claim that:

...the Descent's rationale was always human sexual selection, and that was being justified by evidence across the zoological spectrum. Darwin himself admitted wearily that it was a 'gigantic subject.' And it was all in aid of explaining the human races" (p. 365-6; emphasis added).

They contend that "Darwin would put his utmost into sexual selection because the subject intrigued him, no doubt, but also for a deeper reason: the theory vindicated his lifelong commitment to human brotherhood" (p. 360). Indeed, according to Desmond and Moore, "Darwin had focused overwhelmingly on sexual selection to prove that all people had descended from one stock... sexual selection as explaining man's racial ancestry" is the "pièce de résistance" of the Descent of Man (p. 370; emphasis in original). Thus, on Desmond and Moore's view, the primary reason for Darwin to discuss sexual selection is to explain the racial origins of humans, ${ }^{4}$ and sexual selection forms Darwin's primary argument for different human races.

\footnotetext{
${ }^{3}$ Although as Darwin himself noted (vol. I, p. 229), common descent doesn't decide the issue; one could accept that all humans had a common ancestor and still think that the different races were different species. Indeed, Darwin gave an extended discussion in the chapter entitled, "On the Races of Man" concerning various characterizations of species and the degree to which the races fit them (not well, Darwin argued). He suggested that "it is almost a matter of indifference" whether one says "races," "species" or "sub-species," though he stated the "most appropriate" term for the "so-called races" is sub-species (vol. I, p. 235). These arguments may have been as important as sexual selection was for Darwin's anti-slavery case, as might Darwin's arguments for common mental evolution (see Alter 2007 for discussion of the latter).

${ }^{4}$ Desmond and Moore state, “....sexual selection is critical to our reading of Darwin's morally fired 'human brotherhood' approach; it was central and critical, too, in Darwin's answer to the American South's (and London's) pro-slavery pundits who proclaimed the black and white races as separate species" (p. xix).
} 
Unfortunately for Desmond and Moore, the anti-slavery-centered Darwin is all too similar to the Darwin as traditionally pictured, in this respect: He is not very forthcoming on topics that are controversial, even to his closest friends and colleagues. Many of his statements are ambiguous. For example, according to Desmond and Moore, "He told Wallace that his 'sole reason' for tackling man was to prove that 'sexual selection has played an important part in the promotion of races' (p. 360). But does that mean that he tackled sexual selection in order to tackle man, or that he tackled man in order to tackle sexual selection? Desmond and Moore's interpretation is further called into question when a bit more of Darwin's March 1867 letter to Wallace is examined:

I had intended giving a chapter on man, in as much as many call him (not quite truly) an eminently domesticated animal; but I found the subject too large for a chapter. Nor shall I be capable of treating the subject well, \& my sole reason for taking it up is that I am pretty well convinced that sexual selection has played an important part in the formation of races, \& sexual selection has always been a subject which has interested me much (letter no. 5440).

Darwin's admission that sexual selection had always been a subject that had interested him might mean that explaining the origin of human races was not his primary reason for discussing sexual selection, which is not to deny that it was $a$ reason. However, seen in context, we can see that explaining the origin of human races was clearly not his sole reason. 
To give two other brief examples: Desmond and Moore reveal that Darwin's first use of the term "sexual selection" (although not the first appearance of the ideas behind sexual selection) seems to be in his "scrap ruminations" on Knox's Races of Man in March 1856, around the same time that he was working on his "Big Book" and writing to his correspondents to find out whether different races shared the same ideas of beauty (p. 282). This shows the undeniable interest that Darwin had in using sexual selection to explain the origin of human races, but again, does it mean that the reason for discussing sexual selection is to explain the origin of human races? Similarly, Desmond and Moore uncover Darwin's note on Prichard's Researches into the Physical History of Mankind, stating that 'Man's Sexual characters are like those of tufted Ducks' (p. 284) - but this doesn't say what would have been more of a smoking gun - that tufted duck characters are like those of man, which would have suggested that he was looking for nonhuman animal cases to support his arguments for humans. I find nuggets like these intriguing, and taking all of Desmond and Moore's pieces of evidence together (as they should be taken to appreciate their arguments in full) they are very suggestive. Suggestive, but ambiguous.

Admittedly, some are less ambiguous than others. Indeed, perhaps the passage that is the most supportive of Desmond and Moore's thesis is one that they do not cite; in February 1867, Darwin wrote to Wallace, "The reason of my being so much interested just at present about sexual selection is that I have almost resolved to publish a little essay on the Origin of Mankind, \& I still strongly think... that sexual selection has been the main agent in forming the races of Man" (letter no. 5420). ${ }^{5}$ But I'm not trying to claim that Desmond and Moore are wrong in what they

\footnotetext{
${ }^{5}$ Even here, Darwin's words are qualified; the phrase "just at present" might imply a longstanding interest in sexual selection, which he has now turned to explaining the origin human races.
} 
say about Darwin; I find it difficult to glean motivations from Darwin's letters and other sources given how closely Darwin held his cards to his chest.

Instead, I wish to raise some puzzles which arise if we accept Desmond and Moore's account of Darwin's motivations. As Desmond and Moore note, Darwin ended Part 1 of the Descent by saying:

We have thus far been baffled in all our attempts to account for the differences between the races of man; but there remains one important agency, namely Sexual Selection, which appears to have acted as powerfully on man, as on many other animals... it can be shewn that it would be an inexplicable fact if man had not been modified by this agency, which has acted so powerfully on innumerable animals, both high and low in the scale. It can further be shewn that the differences between the races of man, as in colour, hairyness, form of features, \&c., are of the nature which it might have been expected would have been acted on by sexual selection. But in order to treat this subject in a fitting manner, I have found it necessary to pass the whole animal kingdom in review; I have therefore devoted to it the Second Part of this work (vol. I, p. 249).

This passage seems to support Desmond and Moore's reading of Darwin; Darwin seems to be saying that the whole reason for the extended treatment of non-human animals (ten chapters worth) in Part II of the Descent is to explain the differences between the human races. But Desmond and Moore tell us very little about how Darwin actually argued that sexual selection could explain the human races. They seem to suggest that female choice for aesthetic characters 
can straightforwardly explain the differences between human races if we think (as Darwin did) that those differences are "skin-deep" and "a matter of preference" (p. 373), but his arguments are not at all straightforward. I propose to look at Darwin's fairly complex argument for the origin of human races in detail, something that (as far as I can tell) has not been done before, on the assumption that his published arguments are also relevant for understanding his motivations. Once we do, we will see that his argument is puzzling in a number of respects; not to put too fine a point on it, but it's not a very good argument - by Darwin's own standards. Namely, the way that Darwin explained sexual selection in non-human animals has a number of important differences from the way that he explained sexual selection in humans. ${ }^{6}$ Thus, it does not seem as though the discussion of non-human animals provides very good support for the case for human races. (In contrast, I think that Darwin's arguments are generally excellent, and he makes a much better case for sexual selection in non-human animals).

I proceed by first discussing sexual selection in non-human animals: the phenomena that Darwin sought to explain and his sexual selection explanation itself. I then turn to sexual selection in humans and show how human sexual selection on Darwin's account was different from most cases of sexual selection in non-humans. I then show that even the exceptional cases in nonhuman animals were handled differently from the human cases; Darwin offered reasons for why the exceptional non-human cases were exceptional, but offered no such reasons for humans, which is a bit puzzling if we accept Desmond and Moore's view of things. Finally, I offer some concluding thoughts on the implications of these puzzles.

\footnotetext{
${ }^{6}$ Darwin did acknowledge in the same passage that he could not "pretend that the effects of sexual selection can be indicated with scientific precision"; my point will be that, even so, the analogies between non-human and human cases do not hold up very well.
} 


\section{Sexual selection in non-human animals}

Darwin first introduced the idea of sexual selection in print in the Origin of Species (1859), but the more developed account appears in the Descent of Man. For that reason, I think it is best to focus on the account in the Descent, though a point from the Origin is salient here, and that is the extent to which Darwin sought to explain certain types of adaptation:

...the mere existence of individual variability and of some few well-marked varieties, though necessary as the foundation for the work, helps us but little in understanding how species arise in nature. How have all those exquisite adaptations of one part of the organisation to another part, and to the conditions of life, and of one distinct organic being to another being, been perfected? We see these beautiful co-adaptations most plainly in the woodpecker and missletoe; and only a little less plainly in the humblest parasite which clings to the hairs of a quadruped or feathers of a bird; in the structure of the beetle which dives through the water; in the plumed seed which is wafted by the gentlest breeze; in short, we see beautiful adaptations everywhere and in every part of the organic world (Darwin 1859, 60-61).

This appeared in Chapter 3, "The Struggle for Existence," where Darwin was still setting out the conditions for natural selection. But it is clear that adaptations - in particular, adaptations within and between organisms and adaptations to the "conditions of life" - were a central, observed phenomenon of interest, one that Darwin sought to explain via natural selection. Indeed, this is not surprising; the creationist view that Darwin wanted to supplant likewise saw "beautiful 
adaptations everywhere." ${ }^{\prime 7}$ The claim that Darwin intended natural selection to explain these sort of adaptations is fairly well accepted, and so I will not address it further here. ${ }^{8}$

What, then, was sexual selection supposed to explain? It is often stated that Darwin invoked sexual selection in order to explain characters that were not adaptations to the conditions of life, characters that natural selection could not explain. Although this is partially correct, it is important to note that Darwin's examination of sexual selection in the Descent does not begin with so-called "nonadaptive" characters ${ }^{9}$ in general, but rather with a lengthy discussion of secondary sexual characters in particular. Darwin thought that sexual selection, not natural selection, was the primary explanation for the presence of secondary sexual characters, and it is these "nonadaptive" characters that are the main target of Darwin's explanation.

Darwin described secondary sexual characters as differences between the sexes that "are not directly connected with the act of reproduction" (1871 vol. I, 253). Darwin acknowledged that the distinction between primary and secondary sexual characters is often not a clear-cut one. But, he said, there are clear-cut examples of secondary sexual characters; males tend to be larger, stronger, more pugnacious, equipped with more offensive and defensive weapons, more gaudily

\footnotetext{
${ }^{7}$ As Darwin later explained: "I now admit...that in the earlier editions of my 'Origin of Species' I probably attributed too much to the action of natural selection or the survival of the fittest. I have altered the fifth edition of the Origin so as to confine my remarks to adaptive changes of structure. I had not formerly sufficiently considered the existence of many structures which appear to be, as far as we can judge, neither beneficial nor injurious; and this I believe to be one of the greatest oversights as yet detected in my work. I may be permitted to say as some excuse, that I had two distinct objects in view, firstly, to shew that species had not been separately created, and secondly, that natural selection had been the chief agent of change, though largely aided by the inherited effects of habit, and slightly by the direct action of the surrounding conditions. Nevertheless I was not able to annul the influence of my former belief, then widely prevalent, that each species had been purposely created; and this led to my tacitly assuming that every detail of structure, excepting rudiments, was of some special, though unrecognised, service" (1871 vol. I, pp. 152-3).

${ }^{8}$ I don't mean to suggest that adaptation was the only thing that natural selection was intended to explain, but it was certainly one of the primary things.

${ }^{9}$ My reasons for the scare quotes will be explained below.
} 
colored, and endowed with a greater power of song (1871 vol. I, 254). Roughly, these are all characters that (Darwin argued) are indirectly involved in reproduction without being necessary (i.e., directly involved, or required) for it (1871 vol. I, p. 256). That is to say, without certain characters (the primary sexual organs), reproduction cannot occur at all, whereas organisms that were deficient in the relevant secondary sexual characters would reproduce if they were able to find mates, which Darwin thought would probably occur if organisms having superior secondary sexual characters were not present (1871 vol. I, p. 258). Sexual selection explained differences between the sexes that were indirectly involved in reproduction, whereas natural selection explained differences between the sexes that were necessary for reproduction.

Thus, with the goal of explaining secondary sexual characters that were not adapted to the conditions of life, Darwin defined sexual selection as a "kind of selection" that "depends on the advantage which certain individuals have over other individuals of the same sex and species" (1871 vol. I, p. 256). Note that in this presentation of the definition, sexual selection can act on either males or females. Most - but as we shall see, importantly not all - of Darwin's examples of sexual selection involved selection on males; that is, most (but again, not all) involved the advantage that some males had over other males of the same species.

So, then, in what way can "certain individuals" have an "advantage" "over other individuals of the same sex and species, in exclusive relation to reproduction"? And what types of causes perpetuate those advantages?

Famously, Darwin characterized two kinds of "sexual struggle": 
...in the one it is between the individuals of the same sex, generally the male sex, in order to drive away or kill their rivals, the females remaining passive; whilst in the other, the struggle is likewise between the individuals of the same sex, in order to excite or charm those of the opposite sex, generally the females, which no longer remain passive, but select the more agreeable partners (1871 vol. II, p. 398; emphasis added).

In short, the two types are same-sex combat (usually male-male) - the victors are those that obtain mates —and choice of mate based on aesthetic criteria (usually female choosing male). ${ }^{10}$ This is because, Darwin claimed, males are generally more "eager" than females (and thus, have more incentive to fight over and to try to "charm" females), and he offered an explanation as to why this might be so (vol. I, p. 273-4). Generalizing from these two types, we can see that sexual selection is driven by differential abilities by members of the same sex and species to obtain mates, in contrast to natural selection, which is driven by organisms' differential survival and/or reproductive abilities. ${ }^{11}$ Darwin gave innumerable examples of both types of sexual selection; of these, horns or antlers have become the canonical example of secondary sexual characters resulting from male-male combat, whereas the peacock's beautiful tail, in contrast to the drab peahen, has become the canonical example of a secondary sexual character resulting from female choice.

\footnotetext{
${ }^{10}$ See Millstein (2011) for discussion of a synthesis of these two types, and for further discussion of the difference between natural selection and sexual selection. Note also that Darwin briefly mentions yet another type of sexual selection, where some males have sense or locomotive abilities that give them an advantage over other males in finding females (vol. I, p. 257); this type of sexual selection also manifests differential abilities of members of the same sex and species in obtaining mates.

${ }^{11}$ According to Desmond and Moore, Darwin changed his views on this issue, initially thinking that males and not females were choosing.
} 
Darwin acknowledged that "in most cases it is scarcely possible to distinguish between the effects of natural and sexual selection" (1871 vol. I, p. 257). Note, however, that he said that the effects are difficult to distinguish — not that there is no difference or that the effects can never be distinguished. Indeed, Darwin asserted, there are significant differences in the effects of sexual and natural selection:

Sexual selection acts in a less rigorous manner than natural selection. The latter produces its effects by the life or death at all ages of the more or less successful individuals. ${ }^{12}$ Death, indeed, not rarely ensues from the conflicts of rival males. But generally the less successful male merely fails to obtain a female, or obtains later in the season a retarded and less vigorous female, or, if polygamous, obtains fewer females; so that they leave fewer, or less vigorous, or no offspring. In regard to structures acquired through ordinary or natural selection, there is in most cases, as long as the conditions of life remain the same, a limit to the amount of advantageous modification in relation to certain special ends; but in regard to structures adapted to make one male victorious over another, either in fighting or in charming the female, there is no definite limit to the amount of advantageous modification; so that as long as the proper variations arise the work of sexual selection will go on. This circumstance may partly account for the frequent and extraordinary amount of variability presented by secondary sexual characters. Nevertheless, natural selection will determine that characters of this kind shall not be acquired by the victorious males, which would be injurious to them in any high degree, either by expending too much of their vital powers, or by exposing them to any great

\footnotetext{
${ }^{12}$ This characterization of the effects of natural selection seems to neglect the earlier discussion where Darwin suggests that natural selection acts on reproductive abilities (excluding the ability to obtain a mate) as well as survival abilities.
} 
danger. The development, however, of certain structures - of the horns, for instance, in certain stags - has been carried to a wonderful extreme; and in some instances to an extreme which, as far as the general conditions of life are concerned, must be slightly injurious to the male. From this fact we learn that the advantages which favoured males have derived from conquering other males in battle or courtship, and thus leaving a numerous progeny, have been in the long run greater than those derived from rather more perfect adaptation to the external conditions of life (1871 vol. I, p. 278-9).

It is tempting to summarize this passage by saying that sexual selection produces, and thus explains, characters that are nonadaptive, where "nonadaptive" ranges from neutral to "slightly injurious," in contrast to natural selection, which leads to adaptations. However, as far as I can tell, Darwin always used "adaptation" and its cognates relationally, as he does here; he contrasted adaptations to the "external conditions of life" with "structures adapted to make one male victorious over another." The former are produced by natural selection and the latter are produced by sexual selection; the characters produced by sexual selection are not adaptations to the conditions of life. It is also worth noting that Darwin often referred to the characters produced by sexual selection as lacking in use or importance.

\section{Sexual selection in humans}

Darwin's discussion of some of the differences between human males and females follow the general pattern of the differences between non-human males and females: for example, Darwin asserted that human males are bigger and stronger because of sexual selection in the form of 
male-male combat. However, Darwin's explanation of human races departed from these canonical examples in two respects. First, while he continued to refer to the characters that differentiated the races as "secondary sexual characters," most of the characters he discussed were the same in males and females - colour, for example. I will discuss this point in further detail below. Second, rather than the females choosing males, in humans, Darwin believed that the males had chosen the females:

With primeval men under the favourable conditions just stated...sexual selection will probably have acted in the following manner. The strongest and most vigorous men,those who could best defend and hunt for their families, and during later times the chiefs or head-men,- - those who were provided with the best weapons and who possessed the most property, such as a larger number of dogs or other animals, would have succeeded in rearing a greater average number of offspring, than would the weaker, poorer and lower members of the same tribes. There can, also, be no doubt that such men would generally have been able to select the more attractive women (vol. II, pp. 368-9).

Desmond and Moore overlook this point, emphasizing the role of female choice in Darwin's thinking. For example:

... sexual selection was the point of the chapter. It would explain how male competition and female choice produced the human races from one ancestral stock (Desmond and Moore, p. 359). ${ }^{13}$

\footnotetext{
${ }^{13}$ Desmond and Moore's sentence continues, “...how men and women picked the desirable traits in their partners, just as breeders picked the traits in their pigeons" (Desmond and Moore, p. 359). So, despite the first part of the sentence, Desmond and Moore do acknowledge male choice in humans. However, they emphasize that female
} 
Moreover, Desmond and Moore do not make special note of the fact that the racial differences in question were generally not sexual differences. Thus, Darwin's arguments appear far more straightforward on their account than they really are.

Darwin acknowledged that the case of humans differed from most of the cases he discussed in the Descent, but pointed out that it did not differ from all such cases:

Other characters proper to the males of the lower animals, such as bright colours and various ornaments, have been acquired by the more attractive males having been preferred by the females. There are, however, exceptional cases in which the males, instead of having been the selected, have been the selectors. We recognise such cases by the females having been rendered more highly ornamented than the males... One such case has been described in the order to which man belongs, namely, with the Rhesus monkey (vol. II, p. 371; emphasis added).

And he explained why he thought that humans were an exceptional case:

Man is more powerful in body and mind than woman, and in the savage state he keeps her in a far more abject state of bondage than does the male of any other animal; therefore it is not surprising that he should have gained the power of selection. Women are everywhere conscious of the value of their beauty; and when they have the means, 
they take more delight in decorating themselves with all sorts of ornaments than do men

(vol. II, pp. 371-2)..$^{14}$

But, Darwin argued (with as many examples as he could muster), standards of beauty are different in different races. Thus, Darwin postulated the origin of human races as follows:

Let us suppose the members of a tribe, in which some form of marriage was practised, to spread over an unoccupied continent; they would soon split up into distinct hordes, which would be separated from each other by various barriers, and still more effectually by the incessant wars between all barbarous nations. The hordes would thus be exposed to slightly different conditions and habits of life, and would sooner or later come to differ in some small degree. As soon as this occurred, each isolated tribe would form for itself a slightly different standard of beauty; and then unconscious selection would come into action through the more powerful and leading savages preferring certain women to others. Thus the differences between the tribes, at first very slight, would gradually and inevitably be increased to a greater and greater degree (vol. II, pp. 370-1).

This passage, and the other passages cited in this section, are not cited by Desmond and Moore. Rather, they state that the case for thinking that Darwin invoked sexual selection primarily to

\footnotetext{
${ }^{14}$ Surely something should be said about Darwin's sexist attitudes towards women here (and see Hubbard 1979 for one such account); however, the issue is complicated. Desmond and Moore document that Darwin initially thought that sexual selection would involve male choice, and only later came to the belief that it involved female choice. From the standpoint of consistency, his argument for sexual selection in humans would have been stronger if female choice prevailed in humans as in most other animals - although perhaps his audience would not have so easily accepted female choice in humans. Perhaps Darwin was persuaded by interlocutors who argued that phenomena such as bride capture showed that human females were not choosing their mates (Desmond and Moore 2009, p. 366). It is also worth noting that Darwin did not rule out female choice in humans entirely: "this form of selection may have occasionally acted during later times; for in utterly barbarous tribes the women have more power in choosing, rejecting, and tempting their lovers, or of afterwards changing their husbands, than might have been expected"; other traits such as beards did not involve sexual selection in humans but were attributed to female choice in an "ancient progenitor" (vol. II, p. 372). None of this is to deny that there is something important to be said about the fact that Darwin thought that female birds chose their mates, but not female humans; again, my point is just that the issue is complicated.
} 
explain the racial origins of humans rests not on the Descent but on letters, notes, etc., and they gloss over Darwin's actual explanation of it. I have not sought to disagree with their evidence; instead, I wish to point out that when one does look at Darwin's arguments in the Descent in detail, a number of puzzles arise.

\section{The Puzzles}

For one, there is an oddity with Darwin's invocation of male choice in the case of humans. After discussing the "curious and not numerous" cases in which female birds are larger and more ornamented than the male, Darwin also invoked male choice, with the females courting the males. But he felt that for male choice to have been present, one of two conditions must have obtained: either "the males in the present class have lost some of that ardour which is usual to their sex, so that they no longer search eagerly for the females" or "the females have become much more numerous than the males" (vol. II, p. 200). Darwin would not have attributed either of these conditions to humans. Thus, male choice in birds is actually disanalogous to male choice in humans. His reasons for endorsing male choice in humans (males far more powerful in mind and body than females) come across as ad hoc; granting Darwin the prejudices of his day, was there really evidence that the differences between male and female humans were so much greater than the differences between males and females of other species? ${ }^{15}$ More importantly, the vast majority of Darwin's cases, which invoke female choice, are even less analogous, and thus do not offer much support for Darwin's argument for different races.

\footnotetext{
${ }^{15}$ As Elisabeth Lloyd (personal communication) pointed out to me, many twentieth-century sociobiologists and evolutionary psychologists followed Darwin in thinking that male choice prevailed in humans, so it is particularly interesting to note how little evidence supported that claim. (See previous footnote for related issues).
} 
Here, one might worry that I have looked to Darwin's analysis of sexual selection in birds rather than his analysis of sexual selection in other mammals or primates. However, recall that Desmond and Moore assert, correctly, that Darwin discussed sexual selection throughout the "whole animal kingdom" in order to explain the origin of human; again, Darwin said as much himself. Moreover, the case for sexual selection in the one primate that Darwin mentioned explicitly in this context - the rhesus monkey - is quite thin. Darwin simply noted that the female rhesus monkeys have a red ring around their tail without offering any additional evidence for male choice. Thus, the analogy to primates similarly offers little support. Evidently, we are simply supposed to see the analogy between the red ring around a female rhesus monkey's tail and the beautiful skin color of a human female.

Similar problems arise when we consider the other way in which Darwin's explanation of human races differed from his canonical cases, namely that the characters that Darwin thought differentiated the races (colour, form of features, etc.) did not, for the most part, differ among the sexes. ${ }^{16}$ However, as there was with mate choice, there were some non-canonical cases among non-humans, where the sexes did not differ in their ornaments. Again, Darwin was explicit in saying that the human case was analogous to the non-human cases:

\footnotetext{
${ }^{16}$ Darwin thought that males and females differed in their hairiness, and that different races also differed in their hairiness. So, one might think that hairiness would make a better case for sexual selection having produced differences in races than skin colour. However, his explanation for hairiness was also quite convoluted. Briefly, he supposed that humans were descended from hairy ancestors, but that females had become less hairy (a feature which he suspected was slightly injurious) through sexual selection prior to the divergence of the different races. He then had to explain why "[s]ome races are much more hairy than others, especially on the male side"; he asserted that this was probably not due to their having retained the primordial condition, but rather that the hairiness was "due to partial reversion, for characters which have long been inherited are always apt to return" (vol. II, p. 378). The only role left for sexual selection in Darwin's explanation of the differences between the races was his assertion that "it is highly probable... that males first acquired their beards as an ornament through sexual selection" (vol. II, p. 379). Here, he had seemingly forgotten that he had just, in the previous section, argued that it was the males who did the choosing in the human species, not the females.
} 
In the previous chapters we have seen that with mammals, birds, fishes, insects, \&c., many characters, which there is every reason to believe were primarily gained through sexual selection by one sex alone, have been transferred to both sexes. As this same form of transmission has apparently prevailed to a large extent with mankind, it will save much useless repetition if we consider the characters peculiar to the male sex together with certain other characters common to both sexes (vol. II, p. 323).

So, let us consider how Darwin thought that characters primarily gained through sexual selection by one sex alone were transferred to both sexes in non-human animals. Darwin noted that "Two distinct elements are included under the term 'inheritance,' namely the transmission and the development of characters; but as these generally go together, the distinction is often overlooked," stating that secondary sexual characters "are transmitted through both sexes, though developed in one alone" (vol. I, p. 279; emphasis added). As is well known, Darwin did not have much evidence for mechanisms of inheritance, but I will leave off a detailed discussion of his views on pangenesis, which are not relevant here. What is relevant, however, is his assertion that "variations which first appear early in life in either sex tend to be developed in both sexes" (vol. I, p. 286). This would tend to be true of the characters that Darwin thought differentiated the races and appeared in both sexes; for example, Darwin made a point of noting the early ages that children of various races develop their skin color (vol. II, p. 318).

To further complicate matters, Darwin undercut the applicability of this generalization to sexual selection by asserting that such variations appearing in youth "which were not of the least service to the young, would run a good chance of being utterly lost" given that "death falls heavily on the weak and inexperienced young" (vol. I, p. 297-8). Since sexual selection occurs only after the "age for reproduction" (vol. I, p. 297), there would be very little of that early variability left 
for sexual selection to act on. In short, the very variations that were required for racial differentiation - those that appeared early in life and were transmitted to both sexes - would rarely tend to be available for sexual selection. Interestingly, Darwin added a postscript in the first issue of the first edition of the Descent, saying that he had "fallen into a serious and unfortunate error" in making this argument, which he had "discovered by working out an illustration in figures," and as he had attempted to show elsewhere, "variations arising early in life have often been accumulated through sexual selection, being then commonly transmitted to both sexes" (vol. II, p. ix). This Postscript is extremely intriguing, and it is tempting to speculate about what really motivated Darwin to write it. ${ }^{17}$ At the least, however, its presence suggests that Darwin did not have his argument for racial differences fully worked out when he began writing the Descent, or he would have realized that his arguments concerning the loss of non-serviceable variations during youth undercut his overall arguments.

Setting Darwin's “error” aside, we are left with his claim that variations that appear in youth tend to be developed in (or "transferred" to) both sexes, and are thus available for sexual selection to act on. This raises a problem, for without sexual differences between males and females, how do we know which characters have been acted on by sexual selection, and which by, for example, natural selection? We have already discussed one difference, namely that sexual selection applies to characters that are not directly involved in survival and reproduction; they do not assist in the "battle of life" and in leaving progeny per se. However, in discussing non-human cases, Darwin provides two other criteria that give evidence that sexual selection has acted on characters appearing in both sexes:

\footnotetext{
${ }^{17}$ I have been unable to find any information on this, however.
} 
1. If there are other species in the same group that have one sex that is similarly coloured, with the other sex being of a different colour (vol. I, p. 322), showing that sexual selection has acted in this group, but with a different inheritance pattern.

2. If the females of almost all of the species in the same group resemble each other more closely in color than do the males, which would indicate that the males have undergone a greater amount of modification than the females (vol. I, p. 410).

The problem here is that (again, taking color as the character in question ${ }^{18}$ ), in humans the males and females of any race do not tend to differ in color. The most that Darwin could say on this score was that "In certain tribes the women are said, whether truly I know not, to differ slightly in tint from the men; and with Europeans, the women are perhaps the more brightly coloured of the two, as may be seen when both sexes have been equally exposed to the weather" (vol. II, p. 316). This is extremely thin, especially as compared to the rest of the Descent, which is on the whole extremely well-documented. ${ }^{19}$ And, of course, there are no other species in our group to compare our skin colors to. Thus, Darwin is forced to admit:

The best kind of evidence that the colour of the skin has been modified through sexual selection is wanting in the case of mankind; for the sexes do not differ in this respect, or only slightly and doubtfully. On the other hand we know from many facts already given that the colour of the skin is regarded by the men of all races as a highly important

\footnotetext{
${ }^{18}$ Darwin had already rejected other explanations for color differences in humans, leaving sexual selection as the most promising explanation (vol. I, pp. 242-249).

${ }^{19}$ Darwin admitted that very few mammals exhibit sexual dimorphism with respect to coloration; the arguments for those that do not, I contend, are thin as well.
} 
element in their beauty; so that it is a character which would be likely to be modified through selection, as has occurred in innumerable instances with the lower animals (vol. II, p. 381).

But as we have seen here, it's not just that the best kind of evidence is lacking; it's really that evidence is almost completely lacking. The two criteria that are usually used in other cases when the sexes are similar cannot be used for humans. His case for sexual selection applying to human races is left to rest on the fact that color is an aspect by which humans are judged beautiful, and mate choice in other species involves aesthetic criteria such as color - even though for all of these other species, additional evidence is available, and even though Darwin thought that some colors in non-human animals were not due to sexual selection, e.g., white coloration in arctic animals.

To summarize the points made in this section: Human races do not fit the vast majority of cases in the Descent, cases in which males and females differ and where there is mate choice, it is the female who is choosing. Moreover, for most of the non-human cases that do not fit this profile, Darwin was able to provide additional evidence that sexual selection had operated, evidence that was not available in the case of humans. His arguments for sexual selection having produced human races are thus relatively weak, and certainly not straightforward.

\section{Concluding Thoughts}

As I suggested at the outset, I have great respect for Desmond and Moore's work and find myself extremely influenced and persuaded by many of their arguments. And I do not think that anything I've said here overturns them. What I have tried to do instead is to raise some puzzles for their argument concerning the centrality of sexual selection for Darwin's thinking about 
human races in particular. As I have tried to show, Darwin's claim that sexual selection could explain human races is not a very good one. It may simply be that he gave the best argument that he could give, and that his best argument was a bit convoluted and a bit short on evidence. But then it seems strange to think, as Desmond and Moore do, that the primary reason for Darwin to discuss sexual selection is to explain the racial origins of humans. The Descent certainly does not give the appearance of a well-planned strategy to use sexual selection to explain the origin of human races, with the discussion of other organisms providing the evidence. There is too much time spent on a multitude of cases that were, by Darwin's own criteria, different from the human case. ${ }^{20}$

So, in light of these puzzles, I suggest an alternate possibility, namely that Darwin may have indeed been motivated to explain human races by his anti-slavery concerns to a greater extent than has been recognized previously (as Desmond and Moore show so beautifully), but that as far as the Descent goes, this was only part of his motivation. Perhaps Darwin, having developed the ideas behind sexual selection, which explained so many otherwise puzzling characters in non-human animals that natural selection could not explain (peacock's tails, long horns, etc.), thought that he might in addition use sexual selection to explain human races. ${ }^{21}$ Indeed, we know from the words of Darwin's own son, not to mention Desmond and Moore's own account, that (Charles) Darwin was also very motivated by his concerns over and interest in non-human

\footnotetext{
${ }^{20}$ Also, if providing an argument against slavery was Darwin's primary motivation, why would Darwin be so determined to refute Wallace, whose views on sexual selection suggested that both sexes having the same color was the usual state (with the females of some species having evolved more drab coloration as a form of protection)? Wallace himself did not apply this account to human races, but Darwin could have. See Schwartz (1984) for a discussion of the extent to which Darwin may have been motivated by refuting Wallace, and Gayon (2010) for an analysis of Darwin's disagreements with Wallace and a discussion of Darwin's views on sexual selection more broadly.

${ }^{21}$ Indeed, Desmond and Moore seem to suggest that Darwin had some of the ideas behind sexual selection and used them to explain phenomena like gaudy courtship displays before he applied them to human races (p. 179).
} 
animals; William Darwin stated that "two subjects which moved my Father perhaps more deeply than any other were cruelty to animals \& slavery - his detestation of both was intense, and his indignation was overwhelming in the case of any levity or want of feeling on these matters" (quoted in Desmond and Moore, p. 357). Thus, the goal of the Descent would be to finally unite humans and non-humans under the same evolutionary process; as Darwin said, there are no "other kinds" and we are all "netted together." Indeed, Darwin sought to show the historical continuity of all organisms and all humans races on the same evolutionary tree. This interpretation would make sense of Darwin's assertion that "The main conclusion arrived at in this work, and now held by many naturalists who are well competent to form a sound judgment, is that man is descended from some less highly organised form" (vol. II, p. 385). It would mean that humans belonged neither at the periphery, nor at the center of Darwin's thinking, but rather that humans and non-humans shared equally in Darwin's field of view.

\section{Acknowledgements}

Thanks to John Beatty, Lisa Gannett, Michael Ghiselin, Oren Harman, John Jackson, Erika Milam, Kevin Padian, Gregory Radick, the Griesemer/Millstein Lab, and attendees of HSS/PSA 2010 and ISHPSSB 2011 for extremely helpful comments at various stages of this project.

\section{References}


Alter, S. G. (2007). Race, language, and mental evolution in Darwin's Descent of Man. Journal of the History of the Behavioral Sciences, 43(3), 239-255.

Darwin, C. Notebook B: [Transmutation of species (1837-1838)]. CUL-DAR121.- Transcribed by Kees Rookmaaker. (Darwin Online, http://darwin-online.org.uk/)

Darwin, C. (1859). On the origin of species by means of natural selection, or the preservation of favoured races in the struggle for life. (First ed.). London: John Murray.

Darwin, C. (1867). “Letter no. 5420.” Darwin Correspondence Project Database. http://www.darwinproject.ac.uk/entry-5420/ (accessed 12 September 2010).

Darwin, C. (1867). "Letter no. 5440.” Darwin Correspondence Project Database. http://www.darwinproject.ac.uk/entry-5440/ (accessed 31 July 2010).

Darwin, C. ([1871] 1981). The descent of man, and selection in relation to sex (First ed.). Princeton: Princeton University Press.

Desmond, A., \& Moore, J. (2009). Darwin's sacred cause. Boston: Houghton Mifflin Harcourt. Gayon, J. (2010). Sexual selection: Another Darwinian process. Comptes Rendus Biologies, 333, $134-144$.

Hubbard, R. (1979). Have only men evolved? In S. Harding \& M. B. Hintikka (Eds.), Discovering Reality (pp. 45-69): Schenkman Publishing Company.

Millstein, R. L. (2011). Sex and sensibility: The role of social selection. Metascience, 20, 258264.

Radick, G. (2009). "Review of A. Desmond and J. Moore's Darwin's Sacred Cause: Race, Slavery and the Quest for Human Origins." Times Higher Education, 12th Feb.

Schwartz, J. S. (1984). Darwin, Wallace, and the 'Descent of Man'. Journal of the History of Biology, 17(2), 271-289. 
